\title{
Comparison and Summary of Two Methods for Determination of Kinematic Viscosity of Organic Heat Carriers in Different Laboratories
}

\author{
Shichun Feng, Dexin Kong, Chunfeng Wang, Linyuan Guo*,Dong Jin \\ China Special Equipment Inspection And Research Institute, Beijing, 100029, China
}

\begin{abstract}
In China, capillary viscometer method is often used to test the kinematic viscosity of organic heat carriers. This method is manually tested and requires cleaning with acetone or petroleum ether, which is easy to cause environmental pollution. In this study, capillary viscometer method and stabinger viscometer method were used to test samples and compare the results. Through data analysis, it was proved that stabinger viscometer method has the advantages of high efficiency, green and environmental protection, and can be applied to accurately determine the kinematic viscosity of organic heat carriers.
\end{abstract}

\section{Introduction}

Organic heat carrier, namely heat conduction liquid, is the organic substance used as heat transfer medium, collectively referred to. ${ }^{[1]}$ Heating technology develops with the development of modern industry. In China, since the 1990s, the application field of organic heat carrier heating technology has expanded rapidly, showing great development potential. As a heat transfer medium, organic heat carrier needs to be tested for multiple physicochemical indexes. Kinematic viscosity is an important physical parameter of organic heat carrier. ${ }^{[2]}$

Kinematic viscosity is used to evaluate the flow performance of crude oil and petroleum products and is an important physical constant in the process of processing, transportation, management, sales and use of crude oil and petroleum products. ${ }^{[3]}$ At the macro level, kinematic viscosity is a measure of the viscosity of organic heat carriers. At the micro level, it reflects the composition and structure of molecules. Therefore, the measurement of kinematic viscosity is very important in theory and engineering. There are many methods for the determination of kinematic viscosity, and the capillary viscometer method is commonly used in China. For example, the Flat capillary viscometer is used for the determination of kinematic viscosity of colorless or light-colored liquid petroleum products, and the countercurrent viscometer is used for the determination of kinematic viscosity of dark-colored petroleum products. ${ }^{[4]}$ However, the method is manual sample detection, and the capillary viscosity tube shall be cleaned manually with acetone or petroleum ether after detection. Among them, acetone is easy to make drugs, while petroleum ether is a dangerous chemical, which will cause human damage and environmental pollution if used in large quantities for a long time. With the development of The Times and the progress of science and technology, automatic viscosity meter arises at the right moment, Stabinger viscometer is one of them, it is the use of liquid viscosity force, by measuring the constant speed driving sample tube light suspension rotor speed, calculate the dynamic viscosity of the sample, and then through the U-shaped shock tube measurement of the density. The kinematic viscosity of the sample is obtained after conversion. ${ }^{[5]}$ This method has the advantages of less sample demand, faster test, convenient cleaning and environmental protection. In order to make the Stabinger viscometer widely used, it is urgent to study the accuracy of the automatic viscometer in the detection of kinematic viscosity.

\section{The experiment}

\subsection{The experimental sample}

We have prepared five unused organic heat carriers, five used organic heat carriers and one kinematic viscosity standard sample (including certificate, $37^{\circ} \mathrm{C}$ ).

\subsection{Instruments and equipment}

Capillary viscometer, Stabinger viscometer

\subsection{The experimental method}

According to GB/T 265-1988 《Determination of Kinematic Viscosity and Calculation of Dynamic Viscosity of Petroleum Products》 and NB/SH/T 08702013 《Determination of Dynamic Viscosity and Density of Petroleum Products and Calculation of Kinematic Viscosity》, capillary viscometer method and 
Stabinger viscometer method were used to test organic heat carrier samples.

\subsubsection{Capillary viscometer method}

The capillary viscometer is shown in Figure 1.

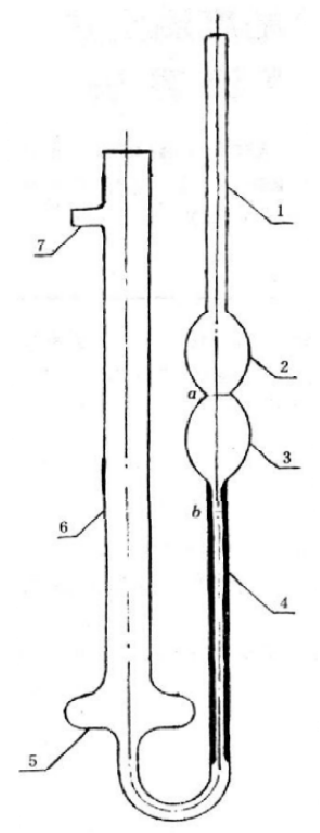

1,6- pipe body; 2,3,5-dilated part; 4-capillary; 7-the glass fork; a, b-marking

Fig. 1.Capillary viscometer.

(1) First, turn on the thermostatic bath and set the temperature at $40{ }^{\circ} \mathrm{C}$. After the temperature is stable, choose a clean and dry viscometer.

(2) Invert the viscometer and insert tube 1 into the sample. At the same time, plug the thick tube opening of tube 6 with the left thumb. Then use the ear-wash ball to suck the sample higher than the mark a at the glass fork 7.Be careful not to create bubbles or cracks in the capillaries and in the dilated part 3.

(3) Straighten the viscometer, fix it in the constant temperature bath, insert a piece of rubber tube on pipe body 1 , and start the test after $20 \mathrm{~min}$.

(4)During the test, the sample was first sucked higher than mark A with an ear-washing ball, and the flow of the sample in the tube was observed. The stopwatch was started when the liquid level reached mark A. Stop the stopwatch when the liquid level reaches mark B.

(5) To check the number of seconds, it is necessary to make the flow time between 200 s $\sim 900$ s. If not, it is necessary to replace the viscosity coefficient with an appropriate capillary viscometer, and continue to repeat steps 2, 3, and 4 until a viscometer meeting the time requirement is found.

(6) After finding an appropriate viscometer, continue to repeat the test according to Step 4 for at least four times, in which the difference between each flow time and its arithmetic mean value should meet the specified requirements (the difference should not exceed $\pm 0.5 \%$ of the arithmetic mean value), and then take the arithmetic mean value obtained from at least three flows as the average flow time of the sample.

(7) The viscometer constants of the capillary viscometer used were obtained and the kinematic viscosity of the sample at $40^{\circ} \mathrm{C}$ was calculated based on the time recorded. See Formula (1) for the calculation formula.

$$
V_{t}=c \cdot V_{t}
$$

Description:

Vt - - - The kinematic viscosity of the sample

C • • • • • Viscometer constant

$\mathrm{Tt} \cdot \cdots \cdot \cdot \cdot$ Average flow time of the sample

\subsubsection{Stabinger viscometer method}

The Stabinger viscosimeter works by injecting samples into a temperature controlled test system, as shown in Figure 2, which consists of a pair of coaxially rotating cylinders (viscosity pools) and a U-shaped vibration tube. During the test, the dynamic viscosity was obtained by measuring the balanced rotation speed and eddy current resistance of the cylinder under the shear stress of the injected sample combined with the calibration data, and then the density was obtained by measuring the vibration frequency of the U-shaped vibration tube combined with the calibration data. The dynamic viscosity at the same temperature was calculated by dividing the density.

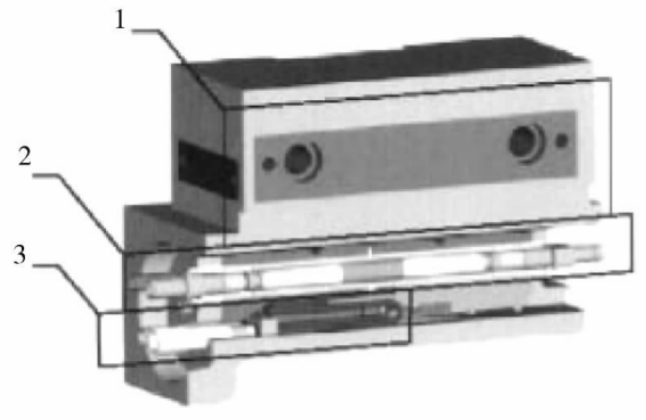

1-Electrical heating and cooling system; 2-Viscosity pool; 3-U-shaped vibration tube

Fig. 2.Stabinger viscosimeter measuring system.

Operation steps are as follows:

(1) First, turn on the instrument and set the temperature at $40^{\circ} \mathrm{C}$. After the temperature is stable, use a $5 \mathrm{~mL}$ syringe to absorb the $5 \mathrm{ml}$ sample, and make sure to remove the bubble in the syringe.

(2)Insert the syringe into the instrument's sample inlet, observe the amount of the sample, stop the sample injection after the sample exceeds the calibration line of the sample outlet (about $1 \mathrm{ml}$ sample), click the start button for testing, and record the value after the display panel is stable. 
(3) Then push the syringe to inject $2 \mathrm{ml}$ sample again, and start the second test. Record the value after the number is stable.

(4)Finally, $1 \mathrm{ml}$ sample was injected for the third test, and the value was recorded after the number was stable.

(5)Take the average of the two closest values of the three records as the final result.

\subsection{Experimental Content}

In this study, 10 blind samples and 1 standard sample were selected for testing, which were jointly completed by five domestic special inspection institutions. Among them, three special inspection institutions tested the samples used in this study by using the Stabinger viscometer method and the capillary viscometer method respectively and compared the data of the results. Then five special inspection institutions using the Stubbinger viscometer method to test the sample, and the results of data comparison.

\section{Results and analysis}

\subsection{Comparison of data between stabinger viscometer and capillary viscometer}

The test results of the three special inspection institutions for the organic heat carrier samples are shown in Table 1 $\sim$ Table 3.The certified value of sample 2019-SX-B at $37{ }^{\circ} \mathrm{C}$ is $23.39 \mathrm{~mm}^{2} / \mathrm{s}$.

Table 1. Comparison data of the two test methods of special inspection Institution A

\begin{tabular}{|c|c|c|c|}
\hline $\begin{array}{c}\text { Sample } \\
\text { number }\end{array}$ & $\begin{array}{c}\text { GB/T 265 } \\
\text { Kinematic } \\
\text { viscosity } \\
\left.\mathbf{( 4 0}{ }^{\circ} \mathbf{C}\right) \\
/ \mathbf{m m}^{2} / \mathbf{s}\end{array}$ & $\begin{array}{c}\text { NB/SH/T0870 } \\
\text { Kinematic } \\
\text { viscosity } \\
\left(\mathbf{4 0} \mathbf{}^{\circ} \mathbf{C}\right) / \mathbf{m m}^{2} / \mathbf{s}\end{array}$ & $\begin{array}{c}\text { RSD( } \\
\text { \%) }\end{array}$ \\
\hline $\begin{array}{c}2019- \\
\text { SX-01 }\end{array}$ & 29.66 & 29.31 & 0.25 \\
\hline $\begin{array}{c}2019- \\
\text { SX-02 }\end{array}$ & 15.04 & 15.16 & 0.08 \\
\hline $\begin{array}{c}2019- \\
\text { SX-03 }\end{array}$ & 18.16 & 18.33 & 0.12 \\
\hline $\begin{array}{c}2019- \\
\text { SX-04 }\end{array}$ & 28.75 & 28.80 & 0.04 \\
\hline $\begin{array}{c}2019- \\
\text { SX-05 }\end{array}$ & 2.555 & 2.533 & 0.02 \\
\hline $\begin{array}{c}2019- \\
\text { SX-06 }\end{array}$ & 29.46 & 30.51 & 0.74 \\
\hline $\begin{array}{c}2019- \\
\text { SX-07 }\end{array}$ & 54.36 & 54.35 & 0.01 \\
\hline $\begin{array}{c}2019- \\
\text { SX-08 }\end{array}$ & 35.88 & 36.77 & 0.63 \\
\hline $\begin{array}{c}2019- \\
\text { SX-09 }\end{array}$ & 16.66 & 16.78 & 0.08 \\
\hline $\begin{array}{c}2019- \\
\text { SX-10 }\end{array}$ & 32.19 & 32.36 & 0.12 \\
\hline $\begin{array}{c}2019- \\
\text { SX-B }\end{array}$ & 23.10 & 23.38 & 0.20 \\
\hline
\end{tabular}

Table 2. Comparison data of the two test methods of special inspection Institution B

\begin{tabular}{|c|c|c|c|}
\hline $\begin{array}{l}\text { Sample } \\
\text { number }\end{array}$ & $\begin{array}{c}\text { GB/T 265 } \\
\text { Kinematic } \\
\text { viscosity } \\
\left(40^{\circ} \mathrm{C}\right) \\
/ \mathrm{mm}^{2} / \mathrm{s}\end{array}$ & $\begin{array}{c}\mathrm{NB} / \mathrm{SH} / \mathrm{T0870} \\
\text { Kinematic } \\
\text { viscosity }\left(40^{\circ} \mathrm{C}\right) \\
/ \mathrm{mm}^{2} / \mathrm{s}\end{array}$ & $\begin{array}{c}\text { RSD( } \\
\%)\end{array}$ \\
\hline $\begin{array}{l}2019- \\
\text { SX-01 }\end{array}$ & 29.29 & 29.18 & 0.08 \\
\hline $\begin{array}{r}2019- \\
\text { SX-02 }\end{array}$ & 15.02 & 15.13 & 0.08 \\
\hline $\begin{array}{l}2019- \\
\text { SX-03 }\end{array}$ & 18.36 & 18.35 & 0.01 \\
\hline $\begin{array}{l}2019- \\
\text { SX-04 }\end{array}$ & 28.63 & 28.72 & 0.06 \\
\hline $\begin{array}{l}2019- \\
\text { SX-05 }\end{array}$ & 2.521 & 2.520 & 0.00 \\
\hline $\begin{array}{l}2019- \\
\text { SX-06 }\end{array}$ & 30.46 & 30.46 & 0.00 \\
\hline $\begin{array}{l}2019- \\
\text { SX-07 }\end{array}$ & 54.37 & 54.37 & 0.00 \\
\hline $\begin{array}{l}2019- \\
\text { SX-08 }\end{array}$ & 36.49 & 36.68 & 0.13 \\
\hline $\begin{array}{l}2019- \\
\text { SX-09 }\end{array}$ & 16.70 & 16.72 & 0.01 \\
\hline $\begin{array}{l}2019- \\
\text { SX-10 }\end{array}$ & 32.26 & 32.06 & 0.14 \\
\hline $\begin{array}{l}2019- \\
\text { SX-B }\end{array}$ & 23.42 & 23.32 & 0.07 \\
\hline
\end{tabular}

Table 3. Comparison data of the two test methods of special inspection Institution C

\begin{tabular}{|c|c|c|c|}
\hline $\begin{array}{l}\text { Sample } \\
\text { number }\end{array}$ & $\begin{array}{c}\text { GB/T } 265 \\
\text { Kinematic } \\
\text { viscosity } \\
\left(40^{\circ} \mathrm{C}\right) \\
/ \mathrm{mm}^{2} / \mathrm{s}\end{array}$ & $\begin{array}{l}\mathrm{NB} / \mathrm{SH} / \mathrm{T0870} \\
\text { Kinematic } \\
\text { viscosity } \\
\left(40^{\circ} \mathrm{C}\right) / \mathrm{mm}^{2} / \mathrm{s}\end{array}$ & $\begin{array}{c}\text { RSD( } \\
\%)\end{array}$ \\
\hline $\begin{array}{l}2019- \\
\text { SX-01 }\end{array}$ & 29.33 & 29.24 & 0.06 \\
\hline $\begin{array}{l}2019- \\
\text { SX-02 }\end{array}$ & 15.21 & 15.08 & 0.09 \\
\hline $\begin{array}{l}2019- \\
\text { SX-03 }\end{array}$ & 18.46 & 18.23 & 0.16 \\
\hline $\begin{array}{l}2019- \\
\text { SX-04 }\end{array}$ & 28.77 & 28.80 & 0.02 \\
\hline $\begin{array}{l}2019- \\
\text { SX-05 } \\
\end{array}$ & 2.481 & 2.562 & 0.06 \\
\hline $\begin{array}{l}2019- \\
\text { SX-06 }\end{array}$ & 30.50 & 30.52 & 0.01 \\
\hline $\begin{array}{l}2019- \\
\text { SX-07 }\end{array}$ & 54.00 & 54.44 & 0.31 \\
\hline $\begin{array}{l}2019- \\
\text { SX-08 }\end{array}$ & 36.59 & 36.82 & 0.16 \\
\hline $\begin{array}{l}2019- \\
\text { SX-09 } \\
\end{array}$ & 16.92 & 16.72 & 0.14 \\
\hline $\begin{array}{l}2019- \\
\text { SX-10 }\end{array}$ & 32.35 & 32.33 & 0.01 \\
\hline $\begin{array}{l}2019- \\
\text { SX-B }\end{array}$ & 23.42 & 23.41 & 0.01 \\
\hline
\end{tabular}

It can be seen from Table 1 to Table 3 that there is no significant difference in the results of different testing methods for organic heat carrier samples by the three special inspection institutions. Then, the comparison data of the test results of the three special inspection 
institutions are fitted linearly, as shown in Figure 3 to Figure 5.

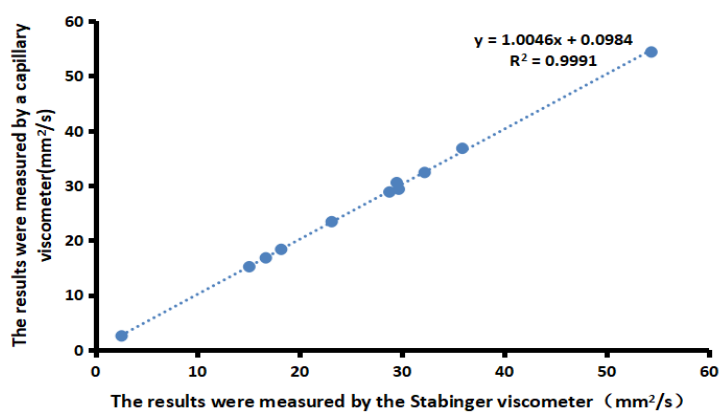

Fig. 3. Comparison of the results of the Stubinger viscometer method and the capillary viscometer method measured by the special inspection Institution A.

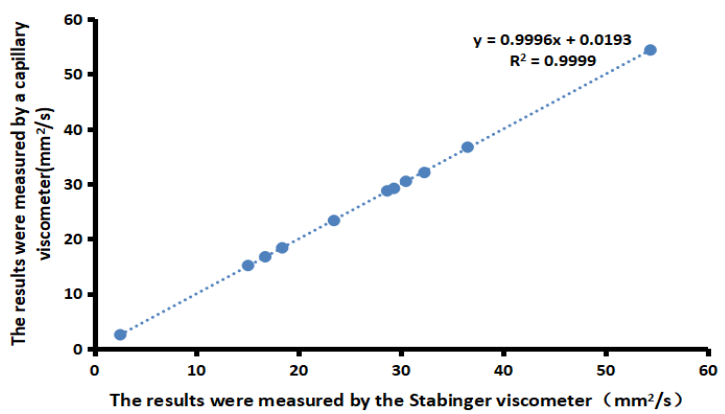

Fig. 4. Comparison of the results of the Stubinger viscometer method and the capillary viscometer method measured by the special inspection Institution B.

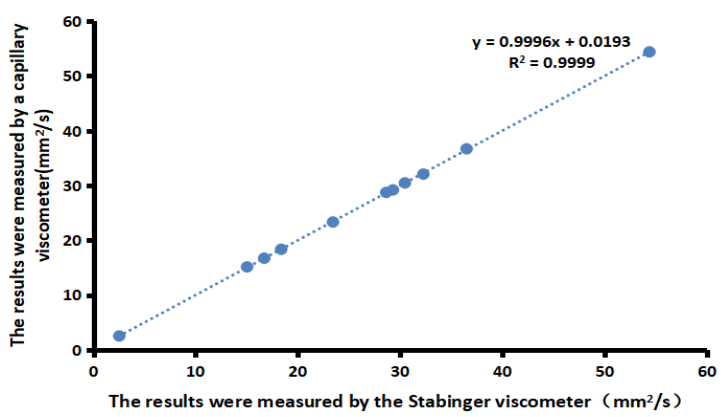

Fig. 5. Comparison of the results of the Stubinger viscometer method and the capillary viscometer method measured by the special inspection Institution C.

As shown in FIG. 3 to FIG. 5, the linear quasi-curve equations of the three special inspection institutions are respectively $y=1.0046 x+0.0984, y=0.9996 x+0.0193$ and $y=1.0098 x-0.2457$, The correlation coefficients are $0.9991,0.9999$ and 0.9999 , Therefore, there is no significant difference between the two methods.

\subsection{Comparison of data between different inspection institutions using The Stabinger viscometer method}

In order to ensure the accuracy and reliability of the results, this study tested the organic heat carrier samples by using the Stabinger viscometer method through five domestic special inspection institutions, and the comparison of the test results is shown in Table 4.

Table 4. Comparison results of the kinematic viscosity of organic heat carriers detected by five research institutes using

The Stabinger viscometer method (Unit: $\mathrm{mm}^{2} / \mathrm{s}$ )

\begin{tabular}{|c|c|c|c|c|c|c|}
\hline $\begin{array}{c}\text { Seri } \\
\text { al } \\
\text { num } \\
\text { ber }\end{array}$ & $\begin{array}{c}\text { Testin } \\
\mathbf{g} \\
\text { instit } \\
\text { utions } \\
\mathbf{1}\end{array}$ & $\begin{array}{c}\text { Testin } \\
\mathbf{g} \\
\text { instit } \\
\text { utions } \\
\mathbf{2}\end{array}$ & $\begin{array}{c}\text { Testin } \\
\mathbf{g} \\
\text { instit } \\
\text { utions } \\
\mathbf{3}\end{array}$ & $\begin{array}{c}\text { Testin } \\
\mathbf{g} \\
\text { instit } \\
\text { utions } \\
\mathbf{4}\end{array}$ & $\begin{array}{c}\text { Testin } \\
\mathbf{g} \\
\text { institu } \\
\text { tions5 }\end{array}$ & $\begin{array}{c}\text { RSD } \\
\mathbf{( \%}\end{array}$ \\
\hline S-1 & 29.22 & 29.31 & 29.35 & 29.18 & 29.24 & 0.24 \\
\hline S-2 & 15.09 & 15.16 & 15.18 & 15.13 & 15.08 & 0.29 \\
\hline S-3 & 18.24 & 18.33 & 18.38 & 18.35 & 18.23 & 0.37 \\
\hline S-4 & 28.68 & 28.80 & 28.86 & 28.72 & 28.80 & 0.25 \\
\hline S-5 & 2.520 & 2.533 & 2.520 & 2.520 & 2.562 & 0.72 \\
\hline S-6 & 30.39 & 30.51 & 30.56 & 30.46 & 30.52 & 0.21 \\
\hline S-7 & 54.13 & 54.35 & 54.38 & 54.37 & 54.44 & 0.22 \\
\hline S-8 & 36.69 & 36.77 & 36.97 & 36.68 & 36.82 & 0.32 \\
\hline S-9 & 16.70 & 16.78 & 16.80 & 16.72 & 16.72 & 0.26 \\
\hline S-10 & 32.07 & 32.36 & 32.37 & 32.06 & 32.33 & 0.49 \\
\hline S-B & 23.32 & 23.38 & 23.44 & 23.32 & 23.41 & 0.23 \\
\hline
\end{tabular}

It can be seen from the table that there is no significant difference in the test results of the five special inspection organizations on the organic heat carrier by using the Stabinger viscometer method. Relative standard deviation (RSD, \%) is used to analyze the accuracy of test results. It can be seen from the table that only the RSD value of no. 5 sample is greater than $0.5 \%$, while the RSD value of other samples is less than $0.5 \%$. In conventional analysis, RSD is required to be less than $5 \%$. In the Chinese pharmacopoeia, the RSD of samples is strictly required to be less than $2 \%$. It can be seen that the experimental data results are all less than $1 \%$, indicating the high precision of the measured results in this experiment.

\section{Conclusion}

In conclusion, the linear fitting of the results measured by the Staenger viscometer and the capillary viscometer shows that there is no significant difference between the two methods. Then through the domestic five special inspection institutions with the results measured by the Stabinger viscometer method, the results measured by the Stabinger viscometer method of high precision, so the Stabinger viscometer method can accurately determine the organic heat carrier viscosity.

The capillary viscometer method also requires a large amount of petroleum ether or acetone for cleaning, with a demand of $15 \mathrm{ml}$, and drying is required after cleaning. Only $10 \mathrm{ml}$ of petroleum ether or acetone is needed to clean the stubbinger viscometer method, which can 
reduce environmental pollution. The operation is simple. After the test, the cleaning only needs to use a syringe to suck $5 \mathrm{ml}$ petroleum ether or acetone and inject it into the sample inlet. The automatic cleaning pump of the instrument can automatically complete blowing and cleaning, which can reduce environmental pollution.

In the test of capillary viscometer method, the sample waits in the constant temperature bath for a long time, and it takes 40 minutes to complete a test. Moreover, the cleaning is manual operation, and the steps are relatively complicated. The Stabinger viscosimeter method is easy to operate and heats up quickly. The system will automatically complete the test after the sample is injected, which only takes 6 minutes. Moreover, the instrument is equipped with automatic cleaning pump. After the test, the switch of the pump will start cleaning automatically, saving labor and time. In the use of hazardous chemicals and time efficiency, the Stabinger viscometer method has a great advantage, with the stabinger automatic viscosity tester test has simple, quick, clean, green advantages.

\section{References}

1. Zhang Jianwen,He Jinkun. Discussion on the influence of kinematic viscosity of organic heat carrier[J]. Construction Materials \& Decoration, 2013, 000(033):84-85.

2. Wang Liulei,Kou Guangxiao,Xu Aixiang. Study on the Influence of Over-temperature on the Viscosity of Liquid Phase Heat Transfer Fluids[D].2018

3. Liao Kwjian,Dai Yueling,Cong Yufeng. Analysis of petrochemical industry[M].Chemical Industry Press, 2005

4. Song Changsheng,Wang Qunwei,Wang Jing,et al.Determination of kinematic viscosity of petroleum products by SVM 3000 Stabinger viscometer[J].Analytical instruments, 2013(6):18-21.

5. Shang Peihua,Song Kaicai,Song Min,et al.The moving viscosity of oil is measured by a Stabinger viscosimeter under rocking conditions[J].Petroleum Products Application Research,2019(2). 